\title{
Effect of advance care planning discussions with trained nurses in older adults with chronic diseases in Japan
}

\author{
Hiroko Okada $^{1}$, Takahiro Kiuchi ${ }^{1} \wedge$, Tsuyoshi Okuhara ${ }^{1 \wedge}$, Yoshiyuki Kizawa $^{2}$ \\ ${ }^{1}$ Department of Health Communication, School of Public Health, The University of Tokyo, Tokyo, Japan; ${ }^{2}$ Department of Palliative Medicine, Kobe \\ University Graduate School of Medicine, Kobe, Japan \\ Contributions: (I) Conception and design: H Okada, T Okuhara, T Kiuchi; (II) Administrative support: Y Kizawa; (III) Provision of study materials \\ or patients: Y Kizawa; (IV) Collection and assembly of data: H Okada; (V) Data analysis and interpretation: All authors; (VI) Manuscript writing: All \\ authors; (VII) Final approval of manuscript: All authors. \\ Correspondence to: Hiroko Okada, RN, PhD. Department of Health Communication, School of Public Health, The University of Tokyo, 7-3-1 \\ Hongo, Bunkyo-ku, Tokyo 113-8655, Japan. Email: okadahiroko-tky@umin.ac.jp.
}

\begin{abstract}
Background Advance care planning (ACP) discussions are often procrastinated due to both physician and patient factors. However, ACP should be started earlier, to provide more time for reviewing one's values and discussing them with loved ones and medical professionals. This study examined the effectiveness of ACP discussions with health care providers held among older adults with chronic diseases.

Methods: This was a non-randomized controlled trial among chronically ill people aged 65 years and older. A 6-month follow-up was conducted in the intervention group, in which participants had ACP discussions with trained nurses $(\mathrm{n}=115)$, and the control group, in which participants did not discuss ACP $(\mathrm{n}=115)$. Questionnaires were administered at baseline and at 6 months, to examine knowledge, ACP readiness and self-efficacy, and comprehensive quality of life (QoL).
\end{abstract}

Results: A total of 200 participants were included in the analysis. The mean age of participants was 69.6 years. There was only a small change in knowledge scores before and after the intervention, with no significant difference between the two groups. ACP engagement was significantly higher in the intervention group than in the control group at 6 months $(\mathrm{P}=0.016)$. Comprehensive QoL was significantly higher in the intervention group than in the control group $(\mathrm{P}<0.001)$. After adjusting for confounders using multiple regression analysis, there was still an association between those higher scores and the intervention $(\mathrm{P}=0.01$, $\mathrm{P}=0.044)$.

Conclusions: This study showed that older adults with chronic diseases can have better communication with their families and health care providers and a higher QoL if they engage in ACP discussions with trained nurses at an early stage.

Keywords: Advance care planning (ACP); end of life discussion; physician-patient relationships; older adults; health communication

Submitted Aug 04, 2021. Accepted for publication Oct 12, 2021.

doi: 10.21037/apm-21-2161

View this article at: https://dx.doi.org/10.21037/apm-21-2161

\section{Introduction}

Advance care planning (ACP) is a decision-making process for end-of-life care in which goals and preferences for future treatment and care are identified and discussed with family members and health care professionals, documented, then reviewed as needed (1). In 2018, the European Association for Palliative Care conducted an international Delphi study to define ACP and recommended elements

\footnotetext{
$\wedge$ ORCID: 0000-0001-7877-9753.
} 
of ACP, including "exploring the individual's experiences, knowledge, values, and preferences about the medical care they will receive in the future" and "appointing a personal representative to discuss their role and options" (1).

There are several benefits to ACP for individuals and families. The benefits for the individual include respect for their values regarding treatment and care, increased autonomy over treatment choices, and increased dialogue with family and health care providers (2-6). For family members, the benefits include reduced burden in decisionmaking and reduced stress and depression after death (7). In addition, patients and family members who had end-of-life discussions with health care providers who had completed communication skills training had a lower risk of developing depression and more frequent communication between health care providers $(8,9)$. However, despite these reported benefits, various countries have reported low rates of ACP completion (10-13).

One important issue in promoting ACP is the timing of when to begin such discussions (14). In a previous large cohort study of patients with colon cancer, the first end-of-life discussion was held 33 days before death, on average (15). Many Japanese people do not feel comfortable discussing the end of life, and it is said that many people want to spend the last part of their lives without having any awareness about death $(16,17)$. Similarly, although health care providers recognize the need for and responsibility to discuss end-of-life care with patients, they avoid or fail to initiate such discussions $(3,18-20)$. As a result of the delay in ACP for these reasons, the question of whether to provide life-sustaining treatment is only addressed after the patient is in very critical condition $(21,22)$. Additionally, the progression of a serious illness often leads to loss of the ability to make medical decisions. Therefore, it is important not to delay the timing of ACP. However, there are no studies in Japan that have examined the impact of early recommendations for and implementation of ACP by health care providers on later life.

The purpose of this study was to clarify the relationship between ACP discussions with medical professionals and knowledge and attitudes about ACP and quality of life (QoL) in older patients with stable chronic diseases. Based on the results of this study, we discuss the expansion of the target group for initiating ACP discussions, from patients who are at serious condition to a wider range of patients who are within the reach of medical professionals.

We present the following article in accordance with the STROBE reporting checklist (available at https://apm. amegroups.com/article/view/10.21037/apm-21-2161/rc).

\section{Methods}

\section{Study design}

This was a non-randomized controlled trial among chronically ill people aged 65 years and older. A 6-month follow-up was conducted in the intervention group, in which participants had ACP discussions with trained nurses, and the control group, in which participants did not discuss ACP. Questionnaires were administered at two time points: pre-intervention and 6 months post-intervention. The intervention was conducted in a conference room in a one-on-one setting. And the questionnaire survey was conducted online by entering responses into a web-based questionnaire. Reminders of the survey were sent by e-mail according to the timing of each target survey.

\section{Ethical considerations}

The study was conducted in accordance with the Declaration of Helsinki (as revised in 2013). All participants received an explanation of the study contents from the researcher before the survey, and the survey system allowed participants to enter their responses to the questionnaire only if they agreed to do so. This study was conducted with the approval of the Ethics Committee of the Faculty of Medicine, University of Tokyo (Application No. 11270).

\section{Participants}

Participants were recruited from people registered with an online research company between January and May 2018. Email was sent to registered users who agreed to participate in the study. Emails were sent to registered users who were willing to participate. Those who could participate in the one-hour intervention were included in the intervention group, and those who could participate only in the questionnaire survey were included in the control group.

The inclusion criteria for both the intervention and control groups were as follows: chronic disease (cardiovascular disease, respiratory disease, malignancy, renal disease, liver disease) with at least one hospital visit every 3 months, never received palliative care services, being independent in daily living activities, and able to go to the hospital on their own. The exclusion criteria were as follows: the investigator judging that the patient had 


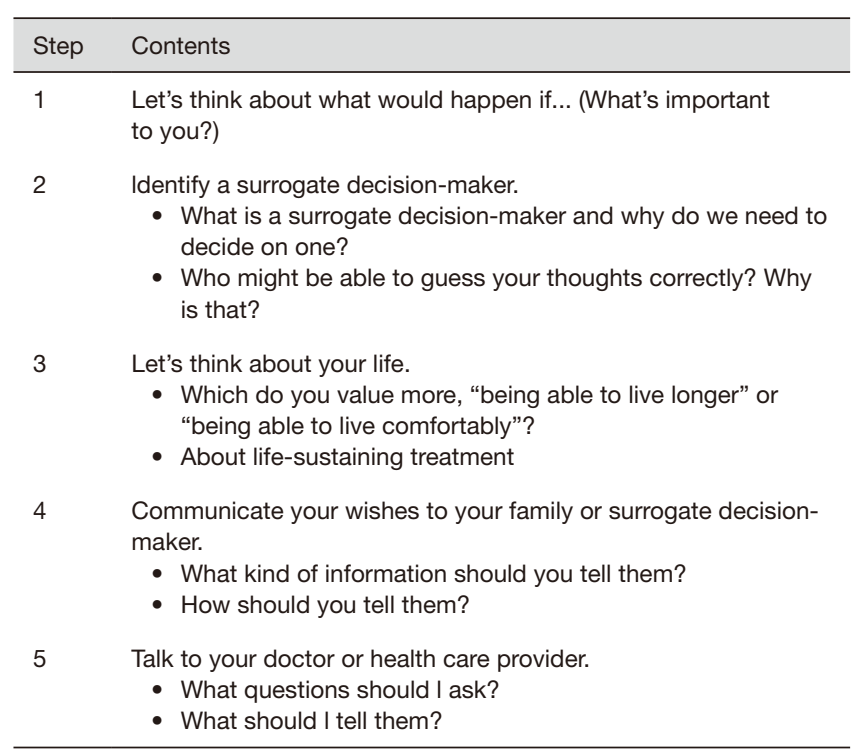

Figure 1 Details of intervention.

difficulty with understanding explanations or completing the questionnaire, the investigator judging that the patient had serious physical or mental symptoms that made it difficult to participate in the study, and the patient having difficulty understanding Japanese.

The sample size was calculated in a $t$-test of the difference in means for the primary endpoint of comprehensive QoL. The effect size was set at 0.4 (Cohen's d), two-sided alpha 0.05 , and power 0.8 from a previous study (23). The calculated sample size was 100 participants in each group. To account for losses to follow-up and drop-outs we set the final sample size to 115 in each group, for total of 230 participants.

\section{Intervention}

Two nurses who completed the 2-day ACP facilitator training conducted the ACP discussion for the intervention group. The training program is the Education for Implementing End-of-Life Discussion (E-FIELD), which consists of lectures, role-plays, and discussions (24). The intervention in this study was the introductory part of the ACP discussion covered in E-FIELD. Details of the intervention are shown in Figure 1, which consisted of five steps. The content required varies depending on the health status of the subject (25). If the patient is healthy or has a mild disease, the end-of-life scenario is more abstract and requires broad and shallow content, such as an exploration of values. For more advanced patients, the assumptions are more specific and focused, such as whether to take, withhold, or terminate a particular treatment. The content of the discussion depends on the situation of the patient and changes from abstract to concrete decision making. The intervention of this study dealt with the introductory part of the ACP discussion for patients with mild chronic illness, which is the concept of a surrogate decision maker, the introductory part of the identification of the person's hopes and values in treatment and life, and the way of communication to share them with the family and medical professionals. Normally, after this, the content would be more specific to the individual's condition depending on the patient's medical condition and situation. Facilitators were also trained in the E-FIELD program to conduct such specific discussions.

The nurses conducted an ACP discussion intervention among study participants in approximately $1 \mathrm{~h}$. To make the intervention content consistent, the nurses provided ACP support based on a common scenario. They also provided examples of other people's narratives that matched each participant's life and disease situation, simulated specific communication to promote ACP with family members and the attending physician, and developed specific plans to promote ACP. Participants in the control group did not receive any of these programs.

\section{Measurement}

\section{Sociodemographic data}

We queried participants' age, sex, education level, history of present illness, severity of each disease, family living together, health literacy, ACP-related experiences, and decision-making preferences. The Charlson comorbidity index (CCI) was used to assess the comorbidity of chronic diseases (26).

For health literacy, we used the Communicative, Critical Health Literacy instrument developed by Ishikawa et al. (27). The scale consists of five items, with five-point Likert scale ( 1 = strongly disagree, to $5=$ strongly agree). The mean is the score. The Cronbach's alpha in this study was 0.87 .

For preferences in the medical decision-making process, based on a control preference scale used in a previous study, we asked, "How you would like your treatment to be decided?" Responses were on a five-point scale $(1=$ I prefer to make the decisions on my own, to $5=\mathrm{I}$ prefer to leave the decisions regarding my treatment completely to my doctor) (28). 


\section{Knowledge about ACP}

A test to assess knowledge about ACP was developed based on a previous study (29). The test consisted of five true/ false questions, e.g., "Effectiveness of cardiopulmonary resuscitation at the end of life" and "Whether or not to change the decision after it has been made". We administered this questionnaire at baseline and 6 months later.

\section{Advance Care Planning Engagement Survey}

The 15-item version of the Advance Care Planning Engagement Survey, developed by Sudore et al., was used to assess participants' ACP processes (self-efficacy and readiness) (30). The full version of this scale developed in 2013 includes 82 items, six shortened versions were developed in 2017 and validated for validity and reliability (31). The 15-item version focuses on two behavior change constructs (self-efficacy and readiness) in four domains (surrogate decision makers, values and QoL, leeway in surrogate decision-making, and asking doctors questions) using a 5-point scale. The mean is the score, and the range is $1-5$. The higher the score, the higher the level of involvement in ACP. In this study, 15 item Japanese version was used only at the second time point (6 months later) because development of the Japanese version had not been completed at the beginning of this study (32). The Cronbach's alpha in this study was 0.93 .

\section{Comprehensive Quality of Life Outcome (CoQoLo) scale}

It has been reported that ACP makes it possible for the patient to reach the end of life in the desired place and circumstances and to achieve what the patient and their family to consider to be a "good death" (33). The CoQoLo is a validated and reliable scale that allows patients themselves to rate the concepts that constitute a "good death" before their own death (23). The original 54 items version and the shortened 18 items version are available, and in this study we used the 18-item version. Each item was evaluated on a seven-point Likert scale ( 1 = totally disagree, to $7=$ totally agree). We administered this questionnaire at baseline and at 6 months. The Cronbach's alpha in this study was 0.89 at baseline and 0.84 after 6 months.

\section{Pilot test of the questionnaires}

For the purpose of testing the face validity and content validity of the questionnaire, five chronically ill patients over 65 years old were recruited by snowball sampling and asked to complete the questionnaire. After completing the questionnaire, a structured interview was conducted to check whether the font size and line spacing were appropriate, whether there were any questions that were difficult to understand or to answer, whether questions lacked appropriate response options, and whether there were any questions that participants did not want to answer or that they found offensive. Based on the results, the questionnaire was revised to ensure the face and content validity of the questionnaire.

\section{Statistical analysis}

Descriptive statistics were conducted for each sociodemographic variable.

For knowledge of ACP and QoCoLo, $t$-tests were conducted for group differences in the change from baseline to 6 months. To address confounding bias, multiple regression analysis was conducted, with the change from baseline to 6 months as the dependent variable for each of these two indicators. Independent variables were the presence or absence of ACP discussions, sex, age (years), whether living with family, duration from diagnosis (months), CCI, health literacy, decision-making preferences, ACPrelated experiences, and baseline scores for each. For the QoCoLo, to confirm which question items among the scales were affected by the intervention, we conducted multiple regression analysis with the same independent variables for 8 items related to ACP, out of the total 18 items.

For the ACP Engagement Survey, $t$-tests were conducted for differences between groups. Then, multiple regression analysis was conducted with the score at 6 months as the dependent variable. The dependent variables were: presence or absence of ACP discussions, sex, age (years), whether living with family, duration from diagnosis (months), CCI, health literacy, decision-making preferences, and ACPrelated experiences.

Due to the specifications of online research, no missing values will be generated. In addition, dropouts were not included in the analysis.

All tests were two-sided, with the significance level set at $5 \%$. IBM SPSS version 25 (IBM Corp., Armonk, NY, USA) was used for the analysis.

\section{Results}

We recruited participants who met the eligibility criteria of older adults with chronic diseases and who were 


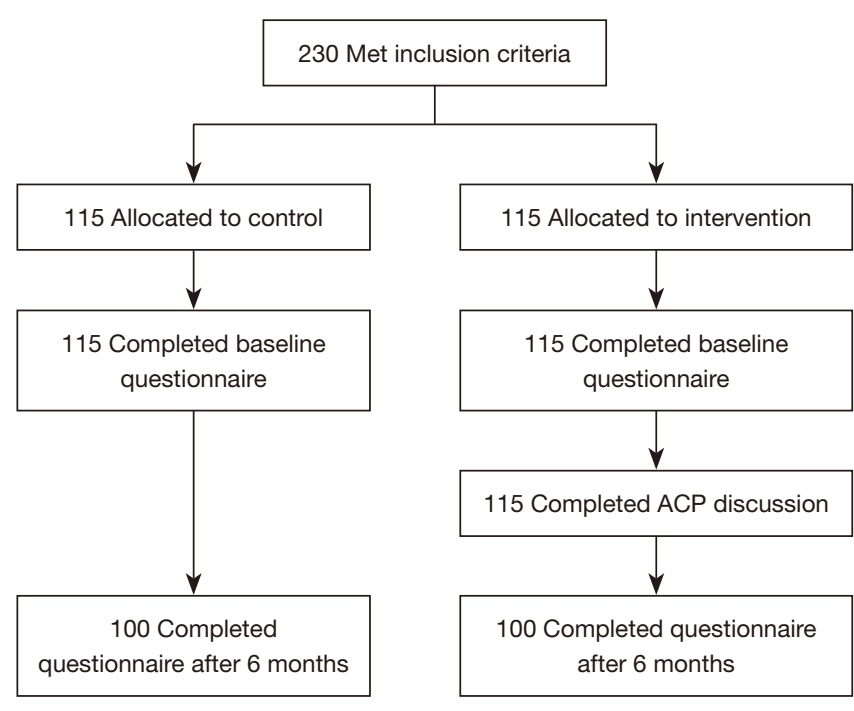

Figure 2 Study flow chart. ACP, advance care planning.

registered with an Internet survey company. A total of 115 participants in the intervention group and 115 participants in the control group consented to participate in the study, and a total of 230 participants responded to the baseline questionnaire. One hundred participants in the intervention group participated in ACP discussions and responded to the questionnaire. Two hundred participants also responded to the survey 6 months after the baseline (follow-up rate: $87 \%)$, and all 200 participants were included in the final analysis (Figure 2). Thirty did not respond to the request and the reason was unknown.

The sociodemographic characteristics of participants in this study are shown in Table 1. The mean participant age was 69.6 years, with the youngest age 65 years, and the oldest 81 years old.

The results of knowledge scores and crude analysis are shown in Table 2 for the overall group and for each group. And the results of multiple regression analysis regarding differences in knowledge scores between the two time points as the dependent variable are shown in Table 3. There was no significant association between the change in knowledge score and the presence of ACP discussion.

The scores for comprehensive QoL and the results of the crude analysis are shown in Table 2. In the intervention group, there was a tendency toward an increase from baseline to 6 months. The results of multiple regression analysis with the change in comprehensive QoL score at two time points as the dependent variable are shown in Table 3. A statistically significant association was detected between the change in comprehensive QoL and the presence of ACP discussions $(\mathrm{P}=0.01)$. The results of multiple regression analysis for the change in each item of the CoQoLo showed a statistically significant association between the presence of ACP discussion in four items: "I feel that it is hard to bother others (reverse scoring: $\mathrm{P}=0.018)$ ", "I am able to spend time in a natural way $(\mathrm{P}=0.006)$ ", "I am able to tell my loved ones what is important to me ( $\mathrm{P}=0.011)$ ", "I am able to ask what I want to know about what will happen in the future $(\mathrm{P}=0.001)$ ".

The ACP Engagement Survey scores at 6 months for the overall group and for each group and the results of the crude analysis are shown in Table 4. The scores tended to be higher in the intervention group than in the control group. The results of multiple regression analysis adjusted for sociodemographic variables are shown in Table 5. A statistically significant association was detected between ACP Engagement Survey scores and the presence of ACP discussions $(\mathrm{P}=0.044)$. In the subscales, only the readiness score showed a significant association with the presence of ACP discussions ( $\mathrm{P}=0.01$; Table 5).

\section{Discussion}

This study examined the effect of ACP discussions on ACP engagement and comprehensive QoL in older adults with chronic diseases by comparing them with a control group. The results showed that having discussions about ACP was associated with higher ACP readiness and higher comprehensive QoL.

\section{Discussion of results}

The ACP process in terms of self-efficacy and readiness was measured using the ACP Engagement Survey. Participants that held ACP discussions tended to be more engaged in ACP than the control group, and the impact of the intervention was particularly seen with regard to readiness. The readiness items of the ACP Engagement Survey were constructed based on the Transtheoretical Model. The result means that the intervention group is in a state that is more likely to take the action of ACP. In this study, a trained nurse presented to each participant narratives of patients with similar diseases at the end of their lives. Narratives from people with similar characteristics evoke greater emotions, are more memorable, and lead to changes in behavior (34). This enabled the participants to imagine the end of life while being exposed to the ideas of people 
Table 1 Participant characteristics

\begin{tabular}{|c|c|c|c|c|}
\hline Variables & Total $(\mathrm{n}=200)$ & Intervention $(\mathrm{n}=100)$ & Control $(n=100)$ & $\mathrm{P}^{*}$ \\
\hline \multicolumn{5}{|l|}{ Sex, n (\%) } \\
\hline Male & $177(88.5)$ & $86(86.0)$ & $91(91.0)$ & 0.268 \\
\hline Female & $23(11.5)$ & $14(14.0)$ & $9(9.0)$ & \\
\hline Age (years), mean \pm SD & $69.6 \pm 3.6$ & $69.3 \pm 3.4$ & $70.0 \pm 3.8$ & 0.155 \\
\hline Junior high school & $2(1.0)$ & $1(1.0)$ & $1(1.0)$ & \\
\hline High school & $39(19.5)$ & $18(18.0)$ & $21(21.0)$ & \\
\hline College & $14(7.0)$ & $7(7.0)$ & $7(7.0)$ & \\
\hline University & $121(60.5)$ & $63(63.0)$ & $58(58.0)$ & \\
\hline Duration from diagnosis (months), mean \pm SD & $134.8 \pm 99.2$ & $157.5 \pm 102.3$ & $112.2 \pm 91.0$ & 0.001 \\
\hline Living with family, n (\%) & & & & 0.428 \\
\hline Yes & $178(89.0)$ & $78(78.0)$ & $90(90.0)$ & \\
\hline No & $22(11.0)$ & $12(12.0)$ & $10(10.0)$ & \\
\hline Health literacy, mean \pm SD & $3.7 \pm 0.6$ & $3.8 \pm 0.6$ & $3.7 \pm 0.6$ & 0.317 \\
\hline Decision-making preferences, n (\%) & & & & 0.110 \\
\hline Active & $12(6.0)$ & $3(3.0)$ & $9(9.0)$ & \\
\hline Active shared & $57(28.5)$ & $26(26.0)$ & $31(31.0)$ & \\
\hline AD/LW & $3(1.5)$ & 0 & $3(3.0)$ & 0.246 \\
\hline
\end{tabular}

*, age, Charlson risk index, duration of illness, and health literacy by $t$-test. Educational level, decision-making preferences, and ACPrelated experiences by Fisher's exact test. Hospitalization experience and living with family by chi-square test. ACP, advance care planning; SD, standard deviation; AD, advance directive; LW, living will.

Table 2 Comparison of knowledge and comprehensive QoL (CoQoLo) with and without ACP discussion

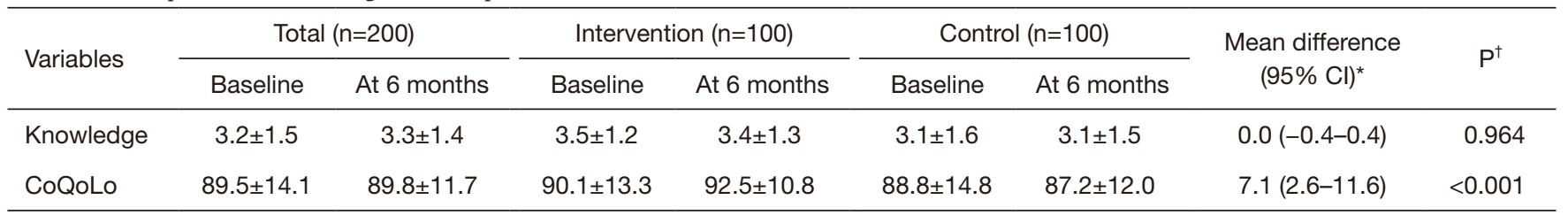

${ }^{*}$, between-group differences in pre-post differences. ${ }^{\dagger}, t$-test for differences. CoQoLo, Comprehensive Quality of Life Outcome; ACP, advance care planning; $\mathrm{Cl}$, confidence interval. 
Table 3 Multiple regression analysis for knowledge and comprehensive QoL (CoQoLo)

\begin{tabular}{|c|c|c|c|c|c|}
\hline Variables & B & $\beta$ & $95 \% \mathrm{Cl}$ & $P^{*}$ & Adjusted $\mathrm{R}^{2}$ \\
\hline Presence of ACP discussion & 0.07 & 0.02 & $-3.48-4.59$ & 0.786 & \\
\hline Sex & 0.10 & 0.21 & $-0.34-0.47$ & 0.748 & \\
\hline Age & -0.13 & -0.33 & $-0.07-0.04$ & 0.621 & \\
\hline Duration from diagnosis & -0.01 & -0.05 & $-0.03-0.01$ & 0.460 & \\
\hline $\mathrm{CCl}$ & -0.41 & -0.44 & $-0.16-0.08$ & 0.513 & \\
\hline Health literacy & 0.43 & 0.18 & $0.11-0.75$ & 0.009 & \\
\hline Decision-making preferences & 0.22 & 0.14 & $0.02-0.43$ & 0.034 & \\
\hline CoQoLo & & & & & 0.24 \\
\hline Presence of ACP discussion & 4.11 & 0.18 & $1.01-7.22$ & 0.010 & \\
\hline Sex & 2.63 & 0.07 & $-2.00-7.26$ & 0.264 & \\
\hline Age & 0.04 & 0.01 & $-0.37-0.46$ & 0.839 & \\
\hline Living with family & 1.87 & 0.05 & $-2.88-6.62$ & 0.438 & \\
\hline Duration from diagnosis & 0.00 & 0.02 & $-0.01-0.02$ & 0.795 & \\
\hline $\mathrm{CCl}$ & 0.04 & 0.01 & $-0.91-0.99$ & 0.937 & \\
\hline Health literacy & 6.97 & 0.36 & $4.47-9.47$ & $<0.001$ & \\
\hline
\end{tabular}

*, multiple regression analysis with the change in ACP knowledge and CoQoLo as dependent variables. CoQoLo, Comprehensive Quality of Life Outcome; ACP, advance care planning; CCI, Charlson comorbidity index; Cl, confidence interval.

Table 4 Comparison of ACP engagement with and without ACP discussion

\begin{tabular}{|c|c|c|c|c|c|}
\hline Variables & Total $(n=200)$ & Intervention $(n=100)$ & Control $(n=100)$ & Mean difference $(95 \% \mathrm{Cl})^{\star}$ & $\mathrm{P}^{\dagger}$ \\
\hline Self-efficacy & $19.1 \pm 6.2$ & $19.4 \pm 6.3$ & $18.7 \pm 6.2$ & $0.8(-1.0-2.5)$ & 0.396 \\
\hline Readiness & $17.0 \pm 8.6$ & $18.8 \pm 9.9$ & $15.2 \pm 6.5$ & $3.6(1.3-6.0)$ & 0.003 \\
\hline
\end{tabular}

*, between-group differences; ${ }^{\dagger}, t$-test for differences. ACP, advance care planning; $\mathrm{Cl}$, confidence interval.

with similar values.

Many Asians, especially the elderly, feel barriers to expressing their opinions to their physician (31). They also do not want to bother the people around them because of them (35). ACP for people with these beliefs does not start with just giving them knowledge and information (35). In this study, nurses who completed the Communication Skills Training for ACP (E-FIELD) conducted the ACP discussion (24). This intervention included simulations of communication in specific situations, such as how to 
Table 5 Multiple regression analysis of ACP engagement

\begin{tabular}{|c|c|c|c|c|c|}
\hline Variables & $\mathrm{B}$ & $\beta$ & $95 \% \mathrm{Cl}$ & $\mathrm{P}^{*}$ & Adjusted $\mathrm{R}^{2}$ \\
\hline Presence of ACP discussion & 0.26 & 0.15 & $0.01-0.52$ & 0.044 & \\
\hline Sex & -0.05 & -0.02 & $-0.41-0.31$ & 0.778 & \\
\hline Age & 0.02 & 0.06 & $-0.02-0.05$ & 0.360 & \\
\hline Duration from diagnosis & 0.00 & -0.08 & $0.00-0.00$ & 0.239 & \\
\hline $\mathrm{CCl}$ & 0.03 & 0.05 & $-0.08-0.21$ & 0.554 & \\
\hline Health literacy & 0.28 & 0.20 & $0.09-0.47$ & 0.004 & \\
\hline Decision-making preferences & -0.04 & -0.04 & $-0.16-0.08$ & 0.520 & \\
\hline Sex & 0.11 & 0.01 & $-2.58-2.81$ & 0.935 & \\
\hline Age & 0.03 & 0.02 & $-0.21-0.27$ & 0.787 & \\
\hline Living with family & -2.22 & -0.11 & $-4.97-0.53$ & 0.115 & \\
\hline Duration from diagnosis & -0.01 & -0.08 & $-0.01-0.00$ & 0.253 & \\
\hline $\mathrm{CCl}$ & 0.18 & 0.05 & $-0.38-0.73$ & 0.530 & \\
\hline Health literacy & 2.57 & 0.25 & $1.15-3.98$ & $<0.001$ & \\
\hline Decision-making preferences & -0.12 & -0.02 & $-1.05-0.80$ & 0.791 & \\
\hline Living with family & -0.80 & -0.03 & $-2.93-4.51$ & 0.673 & \\
\hline Duration from diagnosis & -0.01 & -0.08 & $-0.02-0.01$ & 0.238 & \\
\hline $\mathrm{CCl}$ & 0.71 & 0.13 & $-0.03-1.46$ & 0.061 & \\
\hline Health literacy & 1.67 & 0.12 & $-0.24-3.58$ & 0.086 & \\
\hline Decision-making preferences & -0.42 & -0.05 & $-1.66-0.83$ & 0.510 & \\
\hline ACP-related experience & 3.44 & 0.26 & $1.61-5.28$ & $<0.001$ & \\
\hline
\end{tabular}

*, multiple regression analysis with ACP engagement and subscales (self-efficacy and readiness) as the dependent variable. ACP, advance care planning; $\mathrm{CCl}$, Charlson comorbidity index; $\mathrm{Cl}$, confidence interval.

communicate wishes about treatment and care to physicians and loved ones. Participants that held this ACP discussions tended to be more engaged in ACP than the control group. In CoQoLo scale, the items "I feel that it is hard to bother others (reverse scoring)", "I am able to tell my loved ones what is important to me", and "I am able to ask what I want to know about what will happen in the future" were significantly associated with presence of ACP discussions. It is possible that the communication skills provided to the intervention group had a broad impact not only on ACP, 
but also on communication with physicians and loved ones. For elderly people living with a disease, knowing a method of communication that can be immediately adopted for communication with health care providers and loved ones may contribute to a better QoL as a patient in later life.

Palliative care has the effect of enhancing patient QoL by enabling them to maintain the activities that they value $(36,37)$. However, these benefits are limited by a late start of palliative care $(38,39)$. One of the main barriers to the introduction of palliative care is that communication at the start of palliative care is perceived as a declaration or admission that the patient is at the end of their life (40). By implementing ACP at a time when the patient is physically and mentally stable, the patient can be exposed to information about end-of-life care at an earlier and more stable stage. Thus, when the time comes to introduce palliative care, there may be less resistance to starting the discussion.

\section{Implications for practice}

Previous studies have shown that ACP does not contribute to anxiety, depression, or hopelessness in patients $(7,15,41,42)$. There are also reports of a preference for early ACP, regardless of illness (43). Based on these findings, early ACP is feasible for older adults with chronic diseases. Patients who have the opportunity to be involved in their medical care, such as those with chronic diseases, have the opportunity to initiate ACP discussions with their medical providers early after diagnosis. Nevertheless, some people feel uncomfortable discussing this kind of content. The best time to start a discussion is after recovery from a serious illness or treatment, or when the condition has calmed down, rather than at the time of diagnosis or the beginning of treatment (44). After a serious situation has been overcome, the patient is more aware of the need for ACP. If there are no specific triggers, one way to start is to ask patients about their experience with the death of relatives or friends. Early initiation of ACP may contribute to a higher QoL and higher quality end of life through early introduction of palliative care, in preparation for the future.

\section{Limitations}

This study should be interpreted in consideration of several limitations. First, most participants in this study were men; additional research may be needed to generalize the results to women. Second, participants were informed about the study during the recruitment process, so the study population may include more people who were interested in the study and who were more health conscious than the general population. Finally, although the study was prospective in design and the results were adjustment for measured confounders, the effect of residual confounding cannot be ruled out because of the lack of random assignment.

This study was conducted as a short-term intervention and evaluation with an introductory part of ACP discussion. However, patients' intentions may change as their medical conditions and treatments change. ACP should be ongoing and should be reviewed periodically. Trained facilitator should lead ongoing ACP discussion, triggered by changes in medical conditions or treatment, to sustain treatment and life according to the patient's wishes. It is then desirable to evaluate the achievement of "good death" for the patient, which is the true purpose of ACP.

\section{Conclusions}

The findings of this study suggested that the introduction of ACP discussions to older adults with chronic diseases prior to serious conditions may increase readiness for ACP and increase comprehensive QoL in later life. Giving older adults living with chronic illnesses specific communication skills to communicate their wishes to health care providers and loved ones has the potential to improve their quality of communication with health care providers and family members in later life. In addition, the results may help to reduce health care providers' psychological barriers to initiating ACP discussions with patients at an early stage.

\section{Acknowledgments}

Funding: None.

\section{Footnote}

Reporting Checklist: The authors have completed the STROBE reporting checklist. Available at https://apm. amegroups.com/article/view/10.21037/apm-21-2161/rc

Data Sharing Statement: Available at https://apm.amegroups. com/article/view/10.21037/apm-21-2161/dss

Conflicts of Interest: All authors have completed the ICMJE uniform disclosure form (available at https://apm. 
amegroups.com/article/view/10.21037/apm-21-2161/coif). The authors have no conflicts of interest to declare.

Ethical Statement: The authors are accountable for all aspects of the work in ensuring that questions related to the accuracy or integrity of any part of the work are appropriately investigated and resolved. The study was conducted in accordance with the Declaration of Helsinki (as revised in 2013). All study participants provided their written informed consent and the study design was approved the Ethics Committee of the Faculty of Medicine, University of Tokyo (Application No. 11270).

Open Access Statement: This is an Open Access article distributed in accordance with the Creative Commons Attribution-NonCommercial-NoDerivs 4.0 International License (CC BY-NC-ND 4.0), which permits the noncommercial replication and distribution of the article with the strict proviso that no changes or edits are made and the original work is properly cited (including links to both the formal publication through the relevant DOI and the license). See: https://creativecommons.org/licenses/by-nc-nd/4.0/.

\section{References}

1. Rietjens JAC, Sudore RL, Connolly M, et al. Definition and recommendations for advance care planning: an international consensus supported by the European Association for Palliative Care. Lancet Oncol 2017;18:e543-51.

2. Morrison RS, Chichin E, Carter J, et al. The effect of a social work intervention to enhance advance care planning documentation in the nursing home. J Am Geriatr Soc 2005;53:290-4.

3. Murray L, Butow PN. Advance care planning in motor neuron disease: A systematic review. Palliat Support Care 2016;14:411-32.

4. Martin RS, Hayes B, Gregorevic K, et al. The Effects of Advance Care Planning Interventions on Nursing Home Residents: A Systematic Review. J Am Med Dir Assoc 2016;17:284-93.

5. Chan KY, Chiu HY, Yap DYH, et al. Impact of structured advance care planning program on patients' wish items and healthcare utilization. Ann Palliat Med 2021;10:1421-30.

6. Modes ME, Heckbert SR, Engelberg RA, et al. PatientReported Receipt of Goal-Concordant Care Among Seriously Ill Outpatients-Prevalence and Associated Factors. J Pain Symptom Manage 2020;60:765-73.
7. Detering KM, Hancock AD, Reade MC, et al. The impact of advance care planning on end of life care in elderly patients: randomised controlled trial. BMJ 2010;340:c1345.

8. Briggs LA, Kirchhoff KT, Hammes BJ, et al. Patientcentered advance care planning in special patient populations: a pilot study. J Prof Nurs 2004;20:47-58.

9. Lyon ME, Garvie PA, McCarter R, et al. Who will speak for me? Improving end-of-life decision-making for adolescents with HIV and their families. Pediatrics 2009;123:e199-206.

10. Aw D, Hayhoe B, Smajdor A, et al. Advance care planning and the older patient. QJM 2012;105:225-30.

11. Evans N, Bausewein C, Meñaca A, et al. A critical review of advance directives in Germany: attitudes, use and healthcare professionals' compliance. Patient Educ Couns 2012;87:277-88.

12. Simon-Lorda P, Tamayo-Velázquez MI, Barrio-Cantalejo IM. Advance directives in Spain. Perspectives from a medical bioethicist approach. Bioethics 2008;22:346-54.

13. van Wijmen MP, Rurup ML, Pasman HR, et al. Advance directives in the Netherlands: an empirical contribution to the exploration of a cross-cultural perspective on advance directives. Bioethics 2010;24:118-26.

14. Sharp T, Moran E, Kuhn I, et al. Do the elderly have a voice? Advance care planning discussions with frail and older individuals: a systematic literature review and narrative synthesis. Br J Gen Pract 2013;63:e657-68.

15. Mack JW, Cronin A, Keating NL, et al. Associations between end-of-life discussion characteristics and care received near death: a prospective cohort study. J Clin Oncol 2012;30:4387-95.

16. Miyashita M, Sanjo M, Morita T, et al. Good death in cancer care: a nationwide quantitative study. Ann Oncol 2007;18:1090-7.

17. Akechi T, Akazawa T, Komori Y, et al. Dignity therapy: Preliminary cross-cultural findings regarding implementation among Japanese advanced cancer patients. Palliat Med 2012;26:768-9.

18. Layson RT, Adelman HM, Wallach PM, et al. Discussions about the use of life-sustaining treatments: a literature review of physicians' and patients' attitudes and practices. End of Life Study Group. J Clin Ethics 1994;5:195-203.

19. Miovic M, Block S. Psychiatric disorders in advanced cancer. Cancer 2007;110:1665-76.

20. Koh SJ, Kim S, Kim J. Communication for end-oflife care planning among Korean patients with terminal cancer: A context-oriented model. Palliat Support Care 2016;14:69-76.

21. Levin TT, Li Y, Weiner JS, et al. How do-not-resuscitate 
orders are utilized in cancer patients: timing relative to death and communication-training implications. Palliat Support Care 2008;6:341-8.

22. Keating NL, Landrum MB, Rogers SO Jr, et al. Physician factors associated with discussions about end-of-life care. Cancer 2010;116:998-1006.

23. Miyashita M, Wada M, Morita T, et al. Development and validation of the Comprehensive Quality of Life Outcome (CoQoLo) inventory for patients with advanced cancer. BMJ Support Palliat Care 2019;9:75-83.

24. Okada H, Morita T, Kiuchi T, et al. Health care providers' knowledge, confidence, difficulties, and practices after completing a communication skills training program for advance care planning discussion in Japan. Ann Palliat Med 2021;10:7225-35.

25. Butler M, Ratner E, McCreedy E, et al. Decision aids for advance care planning: an overview of the state of the science. Ann Intern Med 2014;161:408-18.

26. Schneeweiss S, Seeger JD, Maclure M, et al. Performance of comorbidity scores to control for confounding in epidemiologic studies using claims data. Am J Epidemiol 2001;154:854-64.

27. Ishikawa H, Nomura K, Sato M, et al. Developing a measure of communicative and critical health literacy: a pilot study of Japanese office workers. Health Promot Int 2008;23:269-74.

28. Degner LF, Sloan JA, Venkatesh P. The Control Preferences Scale. Can J Nurs Res 1997;29:21-43.

29. Mitchell SL, Shaffer ML, Cohen S, et al. An Advance Care Planning Video Decision Support Tool for Nursing Home Residents With Advanced Dementia: A Cluster Randomized Clinical Trial. JAMA Intern Med 2018;178:961-9.

30. Sudore RL, Stewart AL, Knight SJ, et al. Development and validation of a questionnaire to detect behavior change in multiple advance care planning behaviors. PLoS One 2013;8:e72465.

31. Sudore RL, Heyland DK, Barnes DE, et al. Measuring Advance Care Planning: Optimizing the Advance Care Planning Engagement Survey. J Pain Symptom Manage 2017;53:669-681.e8.

32. Okada H, Takenouchi S, Okuhara T, et al. Development of a Japanese version of the Advance Care Planning Engagement Survey: Examination of its reliability and validity. Palliat Support Care 2021;19:341-7.

33. Yamaguchi T, Maeda I, Hatano Y, et al. Effects of End-of-
Life Discussions on the Mental Health of Bereaved Family Members and Quality of Patient Death and Care. J Pain Symptom Manage 2017;54:17-26.e1.

34. Hullett CR. Charting the process underlying the change of value-expressive attitudes: The importance of value-relevance in predicting the matching effect. Communication Monographs 2002;69:158-78.

35. Cheng SY, Lin CP, Chan HY, et al. Advance care planning in Asian culture. Jpn J Clin Oncol 2020;50:976-89.

36. Dyar S, Lesperance M, Shannon R, et al. A nurse practitioner directed intervention improves the quality of life of patients with metastatic cancer: results of a randomized pilot study. J Palliat Med 2012;15:890-5.

37. Vanbutsele G, Van Belle S, Surmont V, et al. The effect of early and systematic integration of palliative care in oncology on quality of life and health care use near the end of life: A randomised controlled trial. Eur J Cancer 2020;124:186-93.

38. Bernacki RE, Block SD; American College of Physicians High Value Care Task Force. Communication about serious illness care goals: a review and synthesis of best practices. JAMA Intern Med 2014;174:1994-2003.

39. Ferrell BR. Late referrals to palliative care. J Clin Oncol 2005;23:2588-9.

40. Hawley P. Barriers to Access to Palliative Care. Palliat Care 2017;10:1178224216688887.

41. Clayton JM, Hancock K, Parker S, et al. Sustaining hope when communicating with terminally ill patients and their families: a systematic review. Psychooncology 2008;17:641-59.

42. Emanuel EJ, Fairclough DL, Wolfe P, et al. Talking with terminally ill patients and their caregivers about death, dying, and bereavement: is it stressful? Is it helpful? Arch Intern Med 2004;164:1999-2004.

43. Kubi B, Istl AC, Lee KT, et al. Advance Care Planning in Cancer: Patient Preferences for Personnel and Timing. JCO Oncol Pract 2020;16:e875-83.

44. Fischer GS, Arnold RM, Tulsky JA. Talking to the older adult about advance directives. Clin Geriatr Med 2000;16:239-54.

Cite this article as: Okada H, Kiuchi T, Okuhara T, Kizawa Y. Effect of advance care planning discussions with trained nurses in older adults with chronic diseases in Japan. Ann Palliat Med 2022;11(2):412-422. doi: 10.21037/apm-21-2161 